\title{
Research on Reliability of Supply Chain Using Fuzzy Theory
}

\author{
Tian Lan and Feng Julie Shen
}

\begin{abstract}
A supply chain is a set of organizations directly linked by one or more upstream and downstream flows of products, services, finances, or information from a source to a customer. As the global economic mode transitioned from vertical integration to horizontal integration, several manufacturing companies selected the most outstanding enterprises worldwide to integrate. In order to benefit all of the enterprises that join a supply chain, it is very important to improve the supply chain (SC) to deal with potential crises that may occur and to stimulate the economics. Therefore, the reliability of a supply chain becomes significant. Since the SC is susceptible to a barrage of factors, which are of bound uncertainty and difficult quantification, in this paper, a mathematic assessment model was constructed to evaluate the reliability of SC using fuzzy comprehensive evaluation method and the laws of fuzzy sets. The evaluation experiment showed that the fuzzy assessment method is feasible.
\end{abstract}

Index Terms-Fuzzy evaluation, supply chain, reliability prediction.

\section{INTRODUCTION}

Supply chain management (SCM) is the management of the flow of goods and services [1]. It includes the movement and storage of raw materials, work-in-process inventory, and finished goods from point of origin to point of consumption. Interconnected or interlinked networks, channels and node businesses are involved in the provision of products and services required by end customers in a supply chain.

With market globalization, improvement of living standards of customers, changes in consumption structure and consumption concept, and influence from economics, politics and society, the uncertainty of the business environment faced by enterprises is subsequently aggravated. Enterprises that can adapt to changes in the marketplace quickly and launch new products faster will surpass competitors and gain market share.

In order to increase the ability of response to the market demand, an enterprise, on the one hand, should reform their inner resources, i.e. business process reengineering. On the other hand, an enterprise ought to take advantage of their outer resources as well, collaborate with partners, decrease the response time of $\mathrm{SC}$, and predominate in market shares. As a result, SCM emerges. In a sense, marketing competence in the 21 st century does not exist between whole companies,

Manuscript received March 21, 2016; revised June 7, 2016

Tian Lan is with DongWu Business School of Soochow University, China (e-mail:1310408010@stu.suda.edu.cn).

Feng Julie Shen is with Georgia State University, Robinson College of Business, USA (e-mail:fshen2@emory.edu). but rather, between their supply chains [2], [3].

In general, $\mathrm{SC}$ is a complex net, covering the entire process from material supplier, component supplier, product manufacturer, distributor, and retailer to the final users [4].

Several main factors influence the SC reliability: credibility of enterprises on SC, degree of enterprises integration, the ability of collaborating between the enterprises on SC, SC's risk resistance capacity, level of customer service, policy environment, internet information interoperability, the stability of compact, etc. These factors play synthetical roles in influencing the SC reliability.

Considering the factors affecting the SC reliability are various and involve problems such as bound uncertainty and difficult quantification, traditional forecasting ways [5] have already become incapable of evaluating the SC reliability. A new method, fuzzy evaluation algorithm, was adopted to forecast the SC reliability through multi-goal evaluation approach in fuzzy theory.

\section{FUZZY THEORY}

In the objective world, fuzziness is a prevailing quality of information, while people tend to utilize the certain quantity to describe those indeed vague information. Consequently, the information, which is considered accurate, actually is fuzzy and uncertain to a large extent. Formations existing in the objective world remain transformation and sophistication. Meanwhile, many aspects of object, such as characteristic, linkage, and interaction factors between objects, are all fuzzy. Furthermore, observation and thinking conducted by human are rough. Therefore, a fuzzy conception is more suitable for describing fuzzy characteristic of objective things and phenomena. Based on the local classification theory, fuzzy theory was developed to solve the fuzzy phenomenon prevailing in reality.

In fuzzy theory, the membership function of a fuzzy set is a generalization of indicator function in classical sets. It represents the degree of truth as an extension of valuation. Fuzzy truth represents membership in vaguely defined sets. The membership function has a range covering the interval $(0$, 1) operating on the domain of all possible values. However, the same fuzzy phenomena may have different fuzzy assessments due to differences in experts, expertise, experience, and evaluating laws, as well as fuzzy objects themselves. Most important are choosing an appropriate membership function and determining the degree of truth. Common methods include fuzzy statistical method, fuzzy sequential method, neural network method, and Genetic Algorithm, etc. 
The membership function which represents a fuzzy set $A$ is usually denoted by $\mu_{A}$. For an element e of domain E, the value $\mu_{A}(e)$ is called the membership degree of e in the fuzzy set $A_{\sim}$. The membership degree $\mu_{A}(e)$ quantifies the grade of membership of the element e to the fuzzy set $A$. The value 0 means that $\mathrm{e}$ is not a member of the fuzzy set; the value 1 means that e is fully a member of the fuzzy set. The values between 0 and 1 characterize fuzzy members, which belong to the fuzzy set only partially. Fuzzy set $A$ on domain E can be expressed by zadeh representation as [6], [7]:

$$
A=\mu_{A}\left(e_{1}\right) / e_{1}+\mu_{A}\left(e_{2}\right) / e_{2}+\cdots+\mu_{A}\left(e_{n}\right) / e_{n}
$$

where, $\mu_{A}\left(e_{i}\right) / e_{i}$ denotes the corresponding relation between membership function $\mu_{A}\left(e_{i}\right)$ of $e_{i}$ with respect to fuzzy set $\underset{\sim}{A}$ and $e_{i}$ itself. $\mu_{A}\left(e_{i}\right)$ denotes the menbership degree that the $i$ th element in $E$ domain belongs to fuzzy set $A$. The membership function can be ranged as: $0 \leq \mu_{A}\left(e_{i}\right) \leq 1$. Therefore, fuzzy set $\underset{\sim}{A}$ is entirely described by membership function $\mu_{A}\left(e_{i}\right)$, i.e. membership degree of $e_{i}$ with respect to fuzzy set $A$ which maps $\mu_{A}\left(e_{i}\right)$ to $[0,1]$. The more closely $\mu_{A}\left(e_{i}\right)$ approaches to 1, the more definitely $e_{i}$ belongs to $A$. Vice versa, the more closely $\mu_{A}\left(e_{i}\right)$ approaches to zero, the less definitely $e_{i}$ belongs to $A$.

Fuzzy assessment is a comprehensive assessment based on fuzzy theory. It includes single-target assessment and multi-target assessment. The latter method is used for reliability prediction of supply chain here. The detail process is shown as follows:

\section{A. Set up Influence Factor Set}

$$
X=\left\{x_{1}, x_{2}, \cdots x_{i} \cdots, x_{n}\right\}
$$

$n$ is the number of influence factor

\section{B. Build the Weight Coefficient Set}

Since each factor impacts the assessed object with different influence degree, we endow each factor a weight coefficient $w_{i}$ so as to reflect the importance of each factor with respect to the object. That is, to define the membership function for each factor with respect to the concept "importance", and then to set up weight coefficient set by collecting all influence factors.

$$
W=\left\{w_{1}, w_{2}, \cdots, w_{i}, \cdots w_{n}\right\}
$$

Commonly, every weight factor must be unified and meet non-negative demand. i.e.

$$
\sum_{i=1}^{n} w_{i}=1 \text { and } w_{i} \geq 0
$$

\section{Set up Assessment Set}

Assessment set consists of all possible evaluating results given by valuator.

$$
U=\left\{u_{1}, u_{2}, \cdots, u_{i}, \cdots, u_{m}\right\}
$$

$m=$ the number of assessments

where, $u_{i}$ denotes possible evaluating result

\section{Fuzzy Comprehensive Assessment Matrix}

After evaluating each single factor from factor set, and then determining the membership value of evaluated plant with respect to different factor from assessment set, different single factor assessment set can be obtained. By combining $\mathrm{n}$ factor assessment sets, the general assessment matrix is formed.

$$
R=\left[\begin{array}{l}
R_{1} \\
R_{2} \\
\cdots \\
R_{j} \\
\cdots \\
R_{n}
\end{array}\right]=\left[\begin{array}{llllll}
r_{11} & r_{12} & \cdots & r_{1 j} & \cdots & r_{1 m} \\
r_{21} & r_{22} & \cdots & r_{2 j} & \cdots & r_{2 m} \\
\cdots & & & & & \\
r_{i 1} & r_{i 2} & \cdots & r_{i j} & \cdots & r_{i m} \\
\cdots & & & & & \\
r_{n 1} & r_{n 2} & \cdots & r_{n j} & \cdots & r_{n m}
\end{array}\right]
$$

The fuzzy comprehensive assessment matrix $B$ is developed through the follow equation:

$$
\begin{aligned}
& B=W \circ R
\end{aligned}
$$

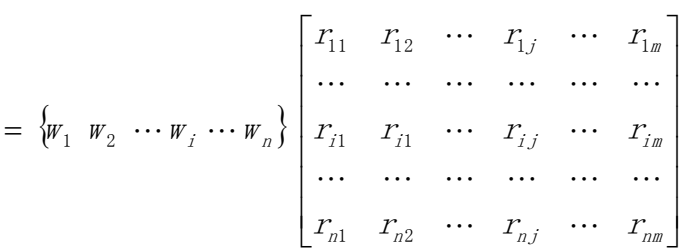

$$
\begin{aligned}
& =\left\{\begin{array}{llllll}
b_{1} & b_{2} & \cdots & b_{i} & \cdots & b_{n}
\end{array}\right\}
\end{aligned}
$$

where, "०" denotes a fuzzy operation. $b_{i}$ is the membership value of $i$ th fuzzy comprehensive assessment element in fuzzy comprehensive assessment set. The fuzzy operation can be run by two operation models as follows:

(1) Model 1: $M(\bullet, \oplus)$ weighted mean model

The calculation equation is

$$
b_{j}=\oplus \sum_{i=1}^{n} w_{i} r_{i j} \quad j=1,2,3 \cdots m
$$

or

$$
b_{j}=\min \left[1, \sum_{i=1}^{n} w_{i} r_{i j}\right]
$$

if $\sum_{i=1}^{n} w_{i}=1, \quad \sum_{i=1}^{n} w_{i} r_{i j} \leq 1$, the model can be modified to:

$M(\bullet,+)$ 
(2) Model 2: $M(\wedge, \vee)$ min operation $(\wedge)$ first, then $\max$ operation $(\vee)$

The matrix calculation equation is

$$
b_{j}=\bigvee_{i=1}^{n}\left(w_{i} \wedge r_{i j}\right) \quad j=1,2,3, \cdots, m
$$

where, " $\wedge$ " - min operation that the smaller value is selected

" $\vee "-—$ max operation that the greater value is selected

\section{Multi-TARget FuZZY AsSESSMENT FOR RELIABILITY PREDICTION OF SC}

$\mathrm{SC}$ is a complex system with both multivariable and non-linear. Factors that impinge on the SC are various and mainly can be divided into two categories: internal causes and external causes. The internal factors may include the enterprise's credit level, SC balance ability, risk resistance capacity, coordinative capacity, etc. The external factors may include policy environment, degrees of interoperability, etc.. Through analysis, several main factors that impinge on the SC are taken as affecting factors [8]-[10]:

(1) Credit of enterprise: long term stability of the compact, quality of product, on-time delivery, maximum of performance, minimum of cost

(2) Balance ability of SC: inventory balance, user demand, costs

(3) Enterprises coordinative capacity on SC: product life cycle, lead time shortening, high average utilization, information exchange and sharing

(4) Risk resistance capacity of SC: demand forecasting, resilience capability, global economics status changing,

(5) Capability of service: fast responsibility, levels of logistics, product renewal and after-sell service

(6) Degrees of interoperability of network information: information technology support, international purchase, SC computerizing

(7) Policy environment: construction of infrastructure, government support program, capability custom clearance

According to the multi-goal fuzzy evaluation method, building the model of multi-goal fuzzy evaluation of SC reliability evaluation, The process is as follow:

\section{A. Affecting Factors Set}

Considering the coupling between factors, pick seven typical factors as the elements in the set:

$X=\left\{x_{1}, x_{2}, x_{3}, x_{4}, x_{5}, x_{6}, x_{7}\right\}=\{$ credit of enterprise, balance ability of SC, enterprises coordinative capacity on SC, risk resistance capacity of SC, capability of service, degrees of interoperability of network information, policy environment .

\section{B. Weight Coefficient}

Due to the credit of enterprises occupied the first place in factors that affect the reliability of SC in the proportion hazard model, take the weight coefficient of credit the largest (the weight of credit of enterprise $=0.3$ ). then follows the order as balance ability of $\mathrm{SC}(0.2)$, enterprises coordinative capacity on $\mathrm{SC}(0.2)$, risk resistance capacity of $\mathrm{SC}(0.05)$, capability of service(0.05), degree of interoperability of network information(0.1), policy environment(0.1). all factors above become the weight set:

$W=\left\{w_{1}, w_{2}, w_{3}, w_{4}, w_{5}, w_{6}, w_{7}\right\}=\{$ credit of enterprise, balance ability of SC, enterprises coordinative capacity on SC, Risk Resistance Capacity of SC, capability of service, degrees of interoperability of network information, policy environment $\}=\{0.3,0.2,0.2,0.05,0.05,0.10 .1\}$

\section{Evaluation Set}

Classify SC reliability evaluation as 5 levels: fairly reliable, reliable, relatively reliable, unreliable, extremely unreliable. The evaluation set is:

$U=\left\{u_{1}, u_{2}, u_{3}, u_{4}, u_{5}\right\}=\{$ fairly reliable, reliable, relatively reliable, unreliable, extremely unreliable

\section{Fuzzy Synthetic Evaluation}

Determine the subjection degree of the elements in the evaluation set to the evaluation object, and form the single factor evaluation set.

(a) Credit of enterprises in the supply chain: excellent, very good, good, average, bad

(b) Balance ability of SC: very strong, strong, average, weak, very weak

(c) Enterprises coordinative capacity on SC: very strong, strong, average, weak, very weak

(d) Risk Resistance Capacity of SC: very strong, strong, average, weak, very weak

(e) Capability of service: excellent, very good, good, average, bad

(f) Degrees of interoperability of network information: very high, high, average, low, very law

(g) Policy environment: excellent, very good, good, average, bad

\section{SC RELIABILITY EVALUATION EXPERIMENT}

Take four examples of SC and build the model of multi-goal fuzzy evaluation of SC reliability. Affecting factors for four practical SC examples are laid in Table I.

TABLE I: AFFECTING FACTORS FOR FOUR PRACTICAL SC EXAMPLES

\begin{tabular}{|l|l|l|l|l|}
\hline & $\begin{array}{l}\text { Communi- } \\
\text { cation } \\
\text { company A }\end{array}$ & $\begin{array}{l}\text { Car } \\
\text { manufacturer } \\
\text { B }\end{array}$ & $\begin{array}{l}\text { Chemistry } \\
\text { company } \\
\text { C }\end{array}$ & $\begin{array}{l}\text { Electronic } \\
\text { company } \\
\text { D }\end{array}$ \\
\hline credits & Level AA & Level AAA & Level A & Level AAA \\
\hline $\begin{array}{l}\text { balance } \\
\text { ability }\end{array}$ & $>93 \%$ & $85 \% \sim 90 \%$ & $80 \% \sim 88 \%$ & $86 \% \sim 92 \%$ \\
\hline coordinate & $\begin{array}{l}\text { in } \\
\text { harmony }\end{array}$ & well & well & in harmony \\
\hline $\begin{array}{l}\text { Risk } \\
\text { Resistance }\end{array}$ & average & Very strong & average & $\begin{array}{l}\text { Very } \\
\text { strong }\end{array}$ \\
\hline service & average & excellent & average & excellent \\
\hline $\begin{array}{l}\text { Information } \\
\text { technology }\end{array}$ & in the lead & advanced & average & advanced \\
\hline policy & $\begin{array}{l}\text { support } \\
\text { partly }\end{array}$ & $\begin{array}{l}\text { support } \\
\text { strongly }\end{array}$ & average & support \\
\hline
\end{tabular}

Four subjection matrix of single factor evaluation through the marking by experts: 


$$
\begin{aligned}
& R_{1}=\left[\begin{array}{ccccc}
0.05 & 0.9 & 0.05 & 0 & 0 \\
0.95 & 0.05 & 0 & 0 & 0 \\
0.9 & 0.1 & 0 & 0 & 0 \\
0 & 0.2 & 0.7 & 0.1 & 0 \\
0 & 0.15 & 0.8 & 0.05 & 0 \\
0.8 & 0.2 & 0 & 0 & 0 \\
0.3 & 0.5 & 0.2 & 0 & 0
\end{array}\right] R_{2}=\left[\begin{array}{ccccc}
0.9 & 0.1 & 0 & 0 & 0 \\
0.7 & 0.2 & 0.1 & 0 & 0 \\
0.4 & 0.5 & 0.1 & 0 & 0 \\
0.8 & 0.2 & 0 & 0 & 0 \\
0.7 & 0.2 & 0.1 & 0 & 0 \\
0.3 & 0.6 & 0.1 & 0 & 0 \\
0.9 & 0.1 & 0 & 0 & 0
\end{array}\right] \\
& R_{3}=\left[\begin{array}{ccccc}
0 & 0.05 & 0.8 & 0.15 & 0 \\
0.2 & 0.7 & 0.1 & 0 & 0 \\
0 & 0.05 & 0.7 & 0.2 & 0.05 \\
0.05 & 0.2 & 0.7 & 0.05 & 0 \\
0 & 0.15 & 0.6 & 0.2 & 0.05 \\
0.05 & 0.3 & 0.6 & 0.05 & 0 \\
0.1 & 0.5 & 0.3 & 0.1 & 0
\end{array}\right] R_{4}=\left[\begin{array}{ccccc}
0.9 & 0.1 & 0 & 0 & 0 \\
0.8 & 0.15 & 0.05 & 0 & 0 \\
0.6 & 0.35 & 0.05 & 0 & 0 \\
0.8 & 0.2 & 0 & 0 & 0 \\
0.7 & 0.2 & 0.1 & 0 & 0 \\
0.3 & 0.6 & 0.1 & 0 & 0 \\
0.8 & 0.15 & 0.05 & 0 & 0
\end{array}\right]
\end{aligned}
$$

Fuzzy synthetic evaluation for reliability of SC by model I:

$$
\begin{aligned}
& B_{1}=W \circ R_{1} \\
& =\left(\begin{array}{lllllll}
0.3 & 0.2 & 0.2 & 0.05 & 0.05 & 0.1 & 0.1
\end{array}\right) \circ\left[\begin{array}{ccccc}
0.05 & 0.9 & 0.05 & 0 & 0 \\
0.95 & 0.05 & 0 & 0 & 0 \\
0.9 & 0.1 & 0 & 0 & 0 \\
0 & 0.2 & 0.7 & 0.1 & 0 \\
0 & 0.15 & 0.8 & 0.05 & 0 \\
0.8 & 0.2 & 0 & 0 & 0 \\
0.3 & 0.5 & 0.2 & 0 & 0
\end{array}\right]
\end{aligned}
$$

$=\left(\begin{array}{lllll}0.495 & 0.3875 & 0.110 & 0.0075 & 0\end{array}\right)=\left(\begin{array}{lllll}b_{11} & b_{12} & b_{13} & b_{14} & b_{15}\end{array}\right)$

For the communication company A, possibilities of degree of SC reliability are as follows: the possibility of fairly reliable is 0.495 , reliable is 0.3875 , relatively reliable 0.11 , unreliable is 0.0075 , extremely unreliable is zero.

Similarly:

$$
\begin{aligned}
& B_{2}=W \circ R_{2}
\end{aligned}
$$

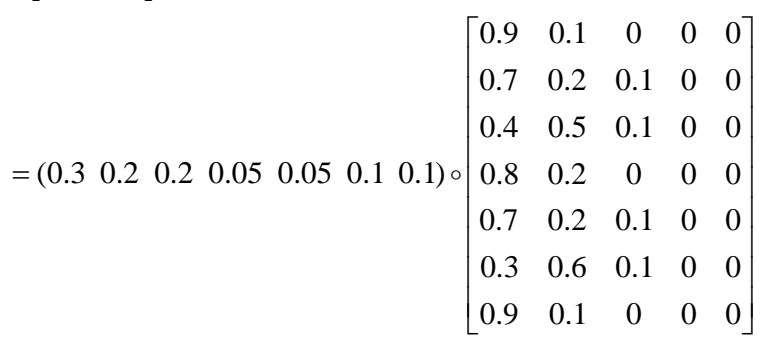$$
=\left(\begin{array}{lllll}
0.685 & 0.260 & 0.055 & 0 & 0
\end{array}\right)=\left(\begin{array}{llllll}
b_{21} & b_{22} & b_{23} & b_{24} & b_{25}
\end{array}\right)
$$

For the car manufacturer B, possibilities of degree of SC reliability are as follows: the possibility of fairly reliable is 0.685 , reliable 0.260 , relatively reliable 0.555 , unreliable 0 , extremely unreliable zero.

$$
\begin{aligned}
& B_{3}=W \circ R_{3} \\
& =\left(\begin{array}{lllllll}
0.3 & 0.2 & 0.2 & 0.05 & 0.05 & 0.1 & 0.1
\end{array}\right) \circ\left[\begin{array}{ccccc}
0 & 0.05 & 0.8 & 0.15 & 0 \\
0.2 & 0.7 & 0.1 & 0 & 0 \\
0 & 0.05 & 0.7 & 0.2 & 0.05 \\
0.05 & 0.2 & 0.7 & 0.05 & 0 \\
0 & 0.15 & 0.6 & 0.2 & 0.05 \\
0.05 & 0.3 & 0.6 & 0.05 & 0 \\
0.1 & 0.5 & 0.3 & 0.1 & 0
\end{array}\right]
\end{aligned}
$$$$
=\left(\begin{array}{lllll}
0.0575 & 0.2605 & 0.555 & 0.1125 & 0.0125
\end{array}\right)=\left(\begin{array}{lllll}
b_{31} & b_{32} & b_{33} & b_{34} & b_{35}
\end{array}\right)
$$

For the Chemistry company $\mathrm{C}$, possibilities of degree of SC reliability are as follows: the possibility of fairly reliable is 0.0575 , reliable 0.2605 , relatively reliable 0.555 , unreliable 0.1125 , extremely unreliable 0.0125 .

$$
\begin{aligned}
& B_{4}=W \circ R_{4} \\
& =\left(\begin{array}{lllllll}
0.3 & 0.2 & 0.2 & 0.05 & 0.05 & 0.1 & 0.1
\end{array}\right) \circ\left[\begin{array}{ccccc}
0.9 & 0.1 & 0 & 0 & 0 \\
0.8 & 0.15 & 0.05 & 0 & 0 \\
0.6 & 0.35 & 0.05 & 0 & 0 \\
0.8 & 0.2 & 0 & 0 & 0 \\
0.7 & 0.2 & 0.1 & 0 & 0 \\
0.3 & 0.6 & 0.1 & 0 & 0 \\
0.8 & 0.15 & 0.05 & 0 & 0
\end{array}\right]
\end{aligned}
$$

$=\left(\begin{array}{lllll}0.735 & 0.245 & 0.040 & 0 & 0\end{array}\right)=\left(\begin{array}{llllll}b_{41} & b_{42} & b_{43} & b_{44} & b_{45}\end{array}\right)$

For the Electronic company D, possibilities of degree of SC reliability are as follows: the possibility of fairly reliable is 0.735 , reliable 0.245 , relatively reliable 0.040 , unreliable 0 , extremely unreliable 0 .

Thus, the order of SC reliability of enterprises is: Electronic company D, car manufacturer B, Communication company A, Chemistry company C

Fuzzy Synthetic Evaluation of SC reliability of four enterprises by model II is as follow:

$$
\begin{aligned}
& B_{1}=W \circ R_{1} \\
& =\left(\begin{array}{lllllll}
0.3 & 0.2 & 0.2 & 0.05 & 0.05 & 0.1 & 0.1
\end{array}\right) \circ\left[\begin{array}{ccccc}
0.05 & 0.9 & 0.05 & 0 & 0 \\
0.95 & 0.05 & 0 & 0 & 0 \\
0.9 & 0.1 & 0 & 0 & 0 \\
0 & 0.2 & 0.7 & 0.1 & 0 \\
0 & 0.15 & 0.8 & 0.05 & 0 \\
0.8 & 0.2 & 0 & 0 & 0 \\
0.3 & 0.5 & 0.2 & 0 & 0
\end{array}\right]
\end{aligned}
$$

$=\left(\begin{array}{lllll}0.2 & 0.3 & 0.1 & 0.05 & 0\end{array}\right)=\left(\begin{array}{lllll}b_{11} & b_{12} & b_{13} & b_{14} & b_{15}\end{array}\right)$

where: $b_{j}=\bigvee_{i=1}^{n}\left(w_{i} \wedge r_{i j}\right)$

Therefore $B_{1}=\left\{\begin{array}{lllll}0.2 & 0.3 & 0.1 & 0.05 & 0\end{array}\right\}$

Similarly, three other enterprises' fuzzy synthetic evaluations are:

$$
\begin{aligned}
& B_{2}=\left\{\begin{array}{lllll}
0.3 & 0.2 & 0.1 & 0 & 0
\end{array}\right\} ; \\
& B_{3}=\left\{\begin{array}{lllll}
0.2 & 0.2 & 0.3 & 0.15 & 0.05
\end{array}\right\} \\
& B_{4}=\left\{\begin{array}{lllll}
0.3 & 0.1 & 0.05 & 0 & 0
\end{array}\right\}
\end{aligned}
$$

To normalize the indexes, $\left(B=\left(\frac{b_{1}}{\sum_{j=1}^{m} b_{j}}, \frac{b_{2}}{\sum_{j=1}^{m} b_{j}}, \cdots, \frac{b_{m}}{\sum_{j=1}^{m} b_{j}}\right)\right.$, we have the indexes of SC reliability of four enterprises

$$
\begin{aligned}
& B_{1}^{\prime}=\left\{\begin{array}{lllll}
\frac{0.2}{0.65} & \frac{0.3}{0.65} & \frac{0.1}{0.65} & \frac{0.05}{0.65} & \frac{0}{0.65}
\end{array}\right\} \\
& =\left\{\begin{array}{lllll}
0.3077 & 0.4615 & 0.1538 & 0.0769 & 0
\end{array}\right\} \\
& B_{2}^{\prime}=\left\{\begin{array}{lllll}
\frac{0.3}{0.6} & \frac{0.2}{0.6} & \frac{0.1}{0.6} & \frac{0}{0.6} & \frac{0}{0.6}
\end{array}\right\} \\
& =\left\{\begin{array}{lllll}
0.5 & 0.3333 & 0.1667 & 0 & 0
\end{array}\right\} \\
& B_{3}^{\prime}=\left\{\begin{array}{lllll}
\frac{0.2}{0.9} & \frac{0.2}{0.9} & \frac{0.3}{0.9} & \frac{0.15}{0.9} & \frac{0.05}{0.9}
\end{array}\right\} \\
& =\left\{\begin{array}{lllll}
0.2222 & 0.2222 & 0.3333 & 0.1667 & 0.0556
\end{array}\right\} \\
& B_{4}^{\prime}=\left\{\begin{array}{ccccc}
\frac{0.3}{0.45} & \frac{0.1}{0.45} & \frac{0.05}{0.45} & \frac{0}{0.45} & \frac{0}{0.45}
\end{array}\right\} \\
& =\left\{\begin{array}{lllll}
0.6667 & 0.2222 & 0.1111 & 0 & 0
\end{array}\right\}
\end{aligned}
$$

Thus, the order of SC reliability of enterprises is: Electronic company D, car manufacturer B, Communication company A, Chemistry company C. 


\section{RESULTS AND ANALYSIS}

As mentioned above, the order of degree of four enterprises' SC reliability forecasted by model I and model II both as follows: electronic company, car manufacturer, communication company, chemistry company. The most prominent place of model $\mathrm{I}$ is that it considers the impact conducted by both $w_{i}$ and $r_{i j}$, maintaining all information so that is better than model II at the aspect of actual result of evaluation. Model II focus on main factors so that its mathematic operation is simple but loses lots of evaluation information, i.e. value of both $w_{i}$ and $r_{i j}$. Thus, two conditions may not be supported by model II: one is that there are lots of evaluation targets but small value of $w_{i}$ and the other is that there are few evaluation targets but large value of $w_{i}$.

\section{CONCLUSION}

In order to improve response time to the demanding, enterprises, on the one hand, must reform the internal resource (business process reengineering). On the other hand, enterprises must make the most of external resource, collaborate with the partners, shorten the response time, and occupy the market as soon as possible. SC reliability is the fundamental of SCM and the security of enterprises to win the marketing shares. Factors with the characteristics of uncertain bound and uneasy to quantification may affect the SC. In this paper, the SC reliability forecasting mathematic model was constructed using multi-goal evaluation method through the fuzzy set algorithm and combined with experience from experts. Fuzzy operation Model I and Model II respectively were applied to forecast the SC reliability through the same experiment data. The results show that both models are acceptable for SC reliability evalutation. Meanwhile, the experiment analysis demonstrates that which model can be chosen separately according to realities of situation.

\section{REFERENCES}

[1] Supply Chain Management (SCM). APICS Dictionary, 19 June, 2013.

[2] F. Wiengarten, B. Fynes, and G. Onofrei, "Exploring synergetic effects between investments in enviromental and quality," Lean Practices in Supply Chains, Supply Chain Management: An International Journal, vol. 18, iss. 2, pp. 148-160, 2013.

[3] S. Janak, "The importance of information flow within the supply chain," Logistics Information Management, vol. 9, no.4, pp. 28-30, 1996.

[4] A. Wieland and C. M. Wallenburg, "The influence of relational competencies on supply chain resilience: A relational view," International Journal of Physical Distribution \& Logistics Management, vol. 43, no. 4, pp. 300-320, 2013.

[5] W. L. G. Buehrer and D. J. Vague, IEEE Trans. on Systems, Man and Cybernetics, vol. 23, no. 2, pp. 610-614, 1993.

[6] D. Chaakraborty and D. Ghosh, "Analytical fuzzy plane geometry II," Fuzzy Sets and Systems, vol. 243, pp. 84-107, 2014.

[7] J. M. Sousa and U. Kaymak, "Model predictive control using fuzzy decision functions," IEEE Trans. SMC, Part B, vol. 31, no. 1, pp. 54-56, 2001.

[8] P. H. Zipkin, Foundation of Inventory Management, McGraw-Hall Higher Education, 2000.

[9] N. C. Petruzzi et al., "The newsvendor model with consumer search cost," Production and Operations Management, vol. 18, no. 6, 2009.

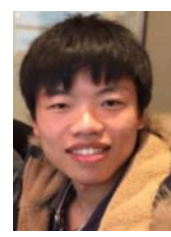

Tian Lan was born in Suzhou, China, 1994. He is a junior student of Dongwu business school of Soochow University. His major is e-business. His interests include supply chain management, e-business, and international trade.

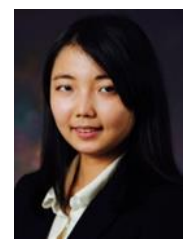

Feng Julie Shen was born in Suzhou, China in 1991 She is currently working at KPMG, LLP in Atlanta, GA specializing Japanese Commercial and Federal Tax. Julie received her bachelor of business administration in accounting from Emory University, Goizueta Business School in May 2014 and is pursuing master degree in taxation at Georgia State, Robinson College of Business. 